\title{
LETTERS
}

\section{Sexism and racism in medical care: It depends on the context}

I commend the authors of recent articles published in $C M A J^{1,2}$ for speaking up against being misidentified and treated with discrimination at work. ${ }^{1,2}$ However, I am also concerned to see the flurry of responses from readers, some of whom seem to be shaming the whistleblowers.

It makes me feel uncomfortable to be misidentified. Despite being a male doctor wearing my name badge, I have been misidentified as a nurse at work. Is it simply because I do not fit the stereotype of a white male doctor? ${ }^{3,4}$ I have also heard patients mispronounce my name as Young, Yuen, and even Yang, as they do other Asian doctors' names. When trying to correct the patients' pronunciation, I have been told, "I do not have your accent" and "you should work on your English." I have been greeted with $\mathrm{Ni} \mathrm{HaO}$ and Xie Xie, and I have been asked to recommend Chinese medicine and acupuncture, even though these are not my scope of practice. In my previous career as a pharmacist, I was sometimes misidentified as a doctor. I did not feel proud of this misidentification and always corrected people. Being misidentified as a nurse could be a compliment to a doctor's caring nature and excellent bedside manner. In other contexts, it could be demeaning: I have heard patients exclaiming, "I cannot believe a woman can be a surgeon!," and I have heard female physicians being repeatedly called nurses, despite wearing their name badges and having introduced themselves as doctors. This sort of misidentification can make any workers feel disrespected, simply because their true identities are not being recognized.

Context matters. It is difficult to judge when you are the outsider in these encounters. Nevertheless, when whistleblowers speak up against discrimination, often they are consequently mocked and shamed, as evidenced by some of the responses to articles calling out sexism or racism. ${ }^{1,5}$

Doctors are reportedly on their own when dealing with discrimination. ${ }^{2}$ It may be wishful thinking to have coworkers stand up for you, as suggested by Manzoor and Redelmeier. ${ }^{1}$ In reality, I often see bystanders keeping their heads down. Moreover, it may be unwise to verbally confront patients, which can result in a disciplinary hearing.

It is time to recognize that communication is a two-way street - it makes no sense that patients can say whatever they want during a professional encounter. Imagine if clinicians frequently misidentified their patients and medical conditions; would the public be fine with that? Regardless of stereotyping and misidentification being intentional or not, this behaviour could make clinicians feel disrespected and uncomfortable.

\section{Eugene Y. H. Yeung MD MSc}

Resident physician, Department of Medical Microbiology, University of Ottawa; Eastern Ontario Regional Laboratory Association, Ottawa, Ont.

Cite as: CMAJ 2020 March 23;192:E323. doi: $10.1503 / \mathrm{cmaj} .74905$

\section{References}

1. Manzoor F, Redelmeier DA. Sexism in medical care: "Nurse, can you get me another blanket?". CMAJ 2020;192:E119-20.

2. Vogel L. Doctors on their own when dealing with racism from patients. CMAJ 2018;190:E1118-9.

3. Vogel L. When people hear "doctor," most still picture a man. CMAJ 2019;191:E295-6.

4. Pezas T. Are surgeons still all privileged white men? BMJ 2016;355:i5513.

5. Alamri B. The Saudi-Canadian dispute: Hidden racism in medical education [blog]. Ottawa: Canadian Medical Association; 2018. Available: cmajblogs.com/the-saudi-canadian-dispute-hidden -racism-in-medical-education (accessed 2020 Feb. 11).

Competing interests: None declared. 